\title{
Hypovitaminosis D in patients on long-term parenteral nutrition
}

\author{
C. T. Tee, A. N. Milestone, A. U. Murugananthan, D. Bernardo and S. M. Gabe \\ Intestinal Failure Unit, St. Mark's Hospital, London HAl 3UJ, UK
}

Emerging evidence shows that vitamin D is not only important for bone integrity but also has immunomodulatory properties. The lowest quartile of 25-hydroxyvitamin D (25-OHD) levels $(<45 \mathrm{nmol} / \mathrm{l})$ is independently associated with all-cause mortality in the general population $^{(1)}$. Patients with intestinal failure (IF) requiring long-term parenteral nutrition (PN) are susceptible to hypovitaminosis D as a result of inadequate absorption, suboptimal vitamin D dietary intake, advanced age, lack of exposure to UVB light and medication influencing vitamin D metabolism. In our institution Cernevit ${ }^{\circledR}$ is added to the PN as required.

We aimed to establish the prevalence of hypovitaminosis D in our tertiary long-term PN patient population. Patients were identified using the St. Mark's IF database. Retrospective data of 25-OHD levels, patient demographics, IF aetiology, month of blood test and vitamin D supplementation prescription were obtained. Cernevit ${ }^{\circledR}$ provided low-dose $(<400$ IU/d) supplementation and intramuscular (IM) injection of $150000 \mathrm{IU}$ vitamin D every 3 months provided a higher dose. Total 25-OHD is defined as severely deficient $(<25 \mathrm{nmol} /$ 1), deficient $(25-50 \mathrm{nmol} / \mathrm{l})$, insufficient $(50-75 \mathrm{nmol} / \mathrm{l})$ and adequate $(>75 \mathrm{nmol} / \mathrm{l})$.

One-hundred-and-ninety-nine PN patients were identified (134 female, median age was 53). The mean duration of PN was 70 months. The mean 25-OHD level was $61.6 \pm 36.5 \mathrm{nmol} / \mathrm{l}$. Vitamin D levels were independent of age $(P=0.37)$, sex $(P=0.52)$ and IF aetiology $(P=0.13)$. Vitamin D levels were higher in summer (June-November, $71.3 \pm 40.8 \mathrm{nmol} / \mathrm{l})$ compared to the winter period $($ DecemberMay, $54.7 \pm 31.6 \mathrm{nmol} / \mathrm{l})(P=0.0015)$. One-hundred-and-forty-three $(71.9 \%)$ patients had vitamin $\mathrm{D}$ levels below $75 \mathrm{nmol} / \mathrm{l} ; 26.6 \%$ were insufficient, $37.2 \%$ were deficient and $8 \%$ were severely deficient. One-hundred-and-sixty-two patients received low dose of vitamin D, 13 received high dose of vitamin D and 24 had no supplements. No significant differences were seen between low-dose and unsupplemented groups $(P>0.05)$. High-dose supplementation significantly increased vitamin D levels $(P<0.05)$ but the levels were still below the recommended level.

\begin{tabular}{lcc}
\hline & Patient No. & Vitamin D levels median (95\% CI) \\
\hline On high-dose supplement & 13 & $70.0(55.2,108.6) *$ \\
On low-dose supplement & 162 & $52.0(54.8,65.4) *$ \\
On no supplement & 24 & $58.0(41.9,80.1)$ \\
\hline$* P=0.0226$ (comparing high- and low-supplement groups). &
\end{tabular}

Hypovitaminosis D $(<75 \mathrm{nmol} / \mathrm{l})$ is common in patients on long-term PN. Gender, age and IF aetiology were not associated with vitamin $\mathrm{D}$ status, but a seasonal variation was seen. The current available intravenous vitamin preparations do not contain an adequate dose of vitamin D for patients on PN. IM supplementation improves vitamin D levels but doses higher than 150000 IU every 3 months is required in this population.

1. Melamed ML, Michos ED, Post W et al. (2008) 25-Hydroxyvitamin D levels and the risk of mortality in the general population. Arch Intern Med 168, $1629-1637$. 